\title{
Knowledge and attitude towards pain management. A comparison between oncology and non-oncology nurses in Jordan
}

\author{
Mona Abed El-Rahman ${ }^{1}$, Mahmoud Taher Al Kalaldeh*², Fakhria Jaber Muhbes ${ }^{3}$ \\ ${ }^{I}$ PhD RN, port said university, Egypt \\ ${ }^{2}$ PhD RN MSN CNS, assistant professor, Zarqa university, Jordan \\ ${ }^{3}$ PhD RN, assistant professor, university of Babylon, Iraq \\ *Corresponding author E-mail: kalaldeh82@yahoo.com
}

\begin{abstract}
Background: Knowledge and attitudes of nurses toward pain management have an influence on medical judgment and patients' perception of pain control. Aim: To assess and compare oncology and non-oncology nurses' knowledge and attitudes toward pain management. Method: A cross sectional descriptive comparative design was used. Nurses were recruited conveniently from one specialized oncology center and one main general medical city in Jordan. Participants were required to complete a specific questionnaire. The total number of participant was 207 nurses (124 oncology and 93 non-oncology nurses). Results: It was evident that oncology nurses received post-registration training or courses in the field of pain management more than non-oncology nurses. Both oncology and non-oncology nurses exhibited an appropriate knowledge and attitude toward pharmacological and non-pharmacological pain management strategies. However, oncology nurses scored higher in the overall knowledge and attitude toward pain compared to non-oncology nurses. Nurses showed knowledge deficit in assuming the risk for addiction and the use of narcotics in pediatric patients. Conclusions: The study revealed that oncology nurses were more knowledgeable compared to non-oncology nurses in managing pain. Professional development for nurses in the field of pain management is required whether during academic preparations or post-graduation.
\end{abstract}

\section{Introduction}

Pain is the most disturbing and annoying symptom experienced by most of the patients. It is subjective symptoms that affect many hospitalized patients and considered an integral part of human experience [1]. Pain may have debilitating effects on patient's physical, emotional and spiritual wellbeing and thus, can alter their quality of life. Recently, it is being measured as one of the vital signs [1,2].

Many nurses gain their perceptions toward pain from their knowledge [3]. Knowledge deficits in this area of practice may yield negative attitudes toward pain management and add to the complexity of pain management $[4,5]$. Patients may become dissatisfied with pain management strategy that is being implemented, which may also alter the state of confidence between patient and nurse [6,7, and 8]. Therefore, nurses are required to gain the appropriate knowledge, attitudes, and practice in managing and accessing pain thoroughly [9, 10, and 11]. However, this area of practice would not be free from nurses' worries about the difficulty to meeting patients' satisfaction and expectation from one side, and the risk for addiction from the another side [10,11]. This multifaceted problem should be anticipated earlier in nursing education programs. For instance, understanding the use and risk of opioid analgesics may become misunderstood in poor academic preparations [12, 13, and 14].

Nurses' are responsible for accurate assessment of pain. Poor pain assessment may contribute to underestimating pain level leading to further anxiety and discomfort to the patient [15, 16, and 17]. In addition, an optimal assessment would enhance positive communication between professionals in which all parties perceive the accurate level and tolerance of patient while he/she undergoes any medical procedure [11, 12, and 13]. Stratton [18] (1999) conducted a 3-year study examining the effectiveness of a pain monitoring program. Nurses' attitudes and behaviors towards pain assessment, interventions, and documentation were assessed. The study found that the knowledge base and attitudes of nurses regarding multiple aspects of pain management are important factors to promote patients' feeling of effective pain 
management. A specialized pain training programs have improved nurses' ability to develop optimal care plans that are inherited with frequent assessment starting from admission to discharge [18].

However, the majority of evidence concerned with nursing practice in pain management emerged from United States, England, and Canada. It is important to aggregate further evidence from different countries assuming that different cultures or backgrounds may introduce different attitudes and beliefs towards pain management [19]. Therefore, this study aimed to add insight towards nursing practice and attitudes in pain management in Jordan especially in comparisons between oncology trained personnel and non-oncology trained personal, suggesting that nurses' ability to deal with chronic pain may be influenced by the area of practice.

\subsection{Aims of the study}

The aim of this study was to assess knowledge and attitudes toward pain management in comparison between Jordanian oncology and non-oncology nurses.

\section{Method}

\subsection{Design and sample}

This cross sectional descriptive comparative study recruited participants from two main medical centers in Jordan; King Hussian Cancer Center and Al-Basher Hospital. The study sample were selected conveniently from nurses who met the criteria which is working in any area concerned with cancer treatment for at least 6 months. Ethical approval from Zarqa University was sought to ensure meeting the required ethical considerations toward participants such as anonymous participation and using the informed consent. The total number of participants was 217 participants (124 oncology nurse, and 93 non-oncology nurse).

\subsection{Study instruments}

A self-administered questionnaire used for this study consisted of two main parts: part (I) included participants' demographics and part (II) included questions related to nurses' knowledge and attitudes toward pain assessment, pharmacological and non-pharmacological pain management. The later consisted of 26 questions were scored according to the degree of agree/disagree using 5 points Liker scale. The instrument consists of both correct and incorrect statements which were obscured to the participant when administered to them. This scale was first used by Zanolin et al. (2007) [20] who also validated the psychometric properties. Construct validity was established to confirm the tool's ability to discriminate between different levels of expertise such as new graduates, oncology nurses, medical-surgical nurses, and senior pain [20].

\subsection{Statistical analysis}

Data were entered into SPSS version 17. Descriptive statistics (frequency, percentage, mean, standard deviation) were used to examine normality of the data and describe the sample. Independent $t$ test and one-way analysis of variance were used to examine the differences in responses scores with categorical demographic variables. A comparison of the demographic information between oncology and non-oncology nurses was completed using Chi-square analysis for nominal data and analysis of variance (ANOVA) for continuous data. Differences between oncology and non-oncology nurses in relation to demographics were tested at the $(\mathrm{p}<0.05)$. The answer to each question in the knowledge and attitudes questionnaires (multiple choices) was calculated either correct or incorrect. The total number of correct responses and the frequency of responses were calculated.

\section{Results}

As shown in Table 1, participants' demographics from both medical centers (217 participants) were compared to each other. Apparently, the majority of participants were female (71.9\%) and hold the bachelor degree in nursing (99.5\%). Although their clinical experiences were closed, $71.8 \%$ of oncology nurses have received at least one post-registration training course about pain management showing a significant difference between groups $(\mathrm{p}=0.006)$. Both oncology and non-oncology nurses did not show any significant difference regarding the use of such references or books of pain management, application of knowledge, and the frequency of using such pain assessment tool. 
Table 1: Participants' demographic characteristics

\begin{tabular}{|c|c|c|c|c|}
\hline Parameter & Oncology Dep. & Non Oncology. & Total & P Value \\
\hline \multicolumn{5}{|l|}{$\operatorname{Sex}($ no, $\%)$} \\
\hline Male & $24(19.4 \%)$ & $37(39.8 \%)$ & $61(28.1 \%)$ & $0.001 *$ \\
\hline Female & $100(80.6 \%)$ & $56(60.2 \%)$ & $156(71.9 \%)$ & \\
\hline Age $(\mathrm{M} \pm \mathrm{SD})$ & $27.84 \pm 4.34$ & $27.12 \pm 3.68$ & $27.53 \pm 4.08$ & 0.199 \\
\hline \multicolumn{5}{|l|}{ Education level } \\
\hline Bachelor & $123(99.2 \%)$ & $93(100.0 \%)$ & $216(99.5 \%)$ & 0.385 \\
\hline Master & $1(0.8 \%)$ & $0(0.0 \%)$ & $1(0.5 \%)$ & \\
\hline Experience (years) & $4.78 \pm 3.72$ & $4.20 \pm 2.33$ & & 0.189 \\
\hline Post registration education & $89(71.8 \%)$ & $50(53.8 \%)$ & & $0.006^{*}$ \\
\hline Reading books or journals & $81(65.3 \%)$ & $54(58.1 \%)$ & & 0.27 \\
\hline Application of knowledge & $95(76.6 \%)$ & $61(65.6 \%)$ & & 0.07 \\
\hline \multicolumn{5}{|c|}{ Frequency of using pain assessment tools } \\
\hline Never & $16(12.9 \%)$ & $9(9.7 \%)$ & & \\
\hline Seldom & $46(37.1 \%)$ & $28(30.1 \%)$ & & 0.23 \\
\hline Often & $52(41.9 \%)$ & $41(44.1 \%)$ & & \\
\hline Every time & $10(8.1 \%)$ & $15(16.1 \%)$ & & \\
\hline
\end{tabular}

\subsection{Knowledge of using pharmacological and non-pharmacological pain management}

In this section, both pharmacological and non-pharmacological pain management items were described in term of appropriateness as perceived by the participants from both medical centers. The comparisons between the oncology and non-oncology nurses were emphasized using the difference in mean scores and significant level.

There were some significant differences between the oncology nurses and non-oncology nurses regarding questions related to the pharmacological pain management as shown in Table 2 despite of similarities in some other questions. Generally nurses in both medical centers perceived appropriately the correct and incorrect uses of the pharmacological pain management strategies thereby correct statements were scored higher in group (a) questions while incorrect statements scored higher in group (b) questions. This pattern of answering was evident in all questions referred to the pharmacological pain management as appeared in Table 2. However, this rule has only been breached in question (9) where oncology nurses did not correctly perceived the use of narcotic in pediatric patients.

The level of accuracy in determining the correct and incorrect questions was scored higher in oncology nurses group than non-oncology nurses group. These considerable differences in the knowledge and attitude yielded a number of significant differences between groups in which means were significantly higher in oncology nurses than non-oncology nurses (Table 2).

Table 2: Comparing oncology and non-oncology nurses in relation to the pharmacological pain management items.

\begin{tabular}{|c|c|c|c|c|c|}
\hline \multirow[t]{2}{*}{ Parameter } & \multicolumn{2}{|c|}{ Oncology } & \multicolumn{2}{|c|}{ Non oncology } & \multirow{2}{*}{$\begin{array}{c}\mathrm{P} \\
\text { value }\end{array}$} \\
\hline & $\begin{array}{l}\text { Correct } \\
\%(a)\end{array}$ & $\begin{array}{l}\text { Incorrect } \\
\%(b)\end{array}$ & $\begin{array}{c}\text { Correct } \\
\%(a)\end{array}$ & $\begin{array}{l}\text { Incorrect } \\
\%(b)\end{array}$ & \\
\hline \multirow{2}{*}{$\begin{array}{l}\text { 1. Giving narcotics on a regular schedule is preferred over "p.r.n." } \\
\text { schedule for continuous pain. (a) }\end{array}$} & 68.6 & 31.4 & 57 & 38.7 & \multirow[t]{2}{*}{$0.007 *$} \\
\hline & \multicolumn{2}{|c|}{ Mean: $3.71 \pm 1.318$} & \multicolumn{2}{|c|}{$3.22 \pm 1.318$} & \\
\hline \multirow{2}{*}{$\begin{array}{l}\text { 2. A patient should experience discomfort prior to giving the next } \\
\text { dose of pain meds. (d) }\end{array}$} & 27.4 & 72.5 & 32.3 & 67.8 & \multirow[t]{2}{*}{0.009} \\
\hline & \multicolumn{2}{|c|}{ Mean: $3.65 \pm 1.230$} & \multicolumn{2}{|c|}{$3.24 \pm 1.026$} & \\
\hline 4. When a patient requests increasing amounts of analgesics to & 25.8 & 74.2 & 28 & 72 & \multirow[t]{2}{*}{$0.049^{*}$} \\
\hline $\begin{array}{l}\text { control pain, this usually indicates that the patient is psychologically } \\
\text { dependent. (d) }\end{array}$ & \multicolumn{2}{|c|}{ Mean: $3.58 \pm 1.162$} & \multicolumn{2}{|c|}{$3.28 \pm 1.036$} & \\
\hline 7. When a patient in pain is receiving analgesic medication on a & 66.1 & 33.9 & 52.7 & 47.3 & $0.001 *$ \\
\hline $\begin{array}{l}\text { "p.r.n." basis, it is appropriate for the patient to request pain meds } \\
\text { before the pain returns. (a) }\end{array}$ & \multicolumn{2}{|c|}{ Mean: $3.57 \pm 1.191$} & \multicolumn{2}{|c|}{$2.91 \pm 1.186$} & \\
\hline \multirow{4}{*}{$\begin{array}{l}\text { 8. Morphine is considered the drug of choice for treatment of } \\
\text { prolonged sever or moderate pain for cancer patient (a) } \\
\text { 9. Because narcotics can cause respiratory depression, they should not } \\
\text { be used in pediatric patients. (d) }\end{array}$} & 74.2 & 25.8 & 64.5 & 35.5 & $0.006^{*}$ \\
\hline & \multicolumn{2}{|c|}{ Mean: $3.90 \pm 1.055$} & \multicolumn{2}{|c|}{$3.51 \pm 1.007$} & \\
\hline & 56.4 & 43.6 & 39.8 & 60.2 & \multirow[b]{2}{*}{$0.001 *$} \\
\hline & Mean: 3 & $.51 \pm 1.253$ & 2.95 & $=1.097$ & \\
\hline \multirow{2}{*}{$\begin{array}{l}\text { 18. Patients having severe chronic pain often need higher dosages of } \\
\text { pain meds than patients with acute pain. (a) }\end{array}$} & 69.4 & 30.6 & 48.4 & 51.6 & \multirow[t]{2}{*}{0.043} \\
\hline & Mean: 3 & $.52 \pm 1.024$ & 3.2 & $=1.036$ & \\
\hline
\end{tabular}

(a) = Correct statement: "agree" or "strongly agree."

$(d)=$ Incorrect statement: "disagree', " "strongly disagree. Or "Neither agrees nor disagrees.* = significant 
Other questions were unfortunately scored incorrectly. For instance, about $33 \%$ of non-oncology nurses and $37 \%$ of oncology nurses did not recognize that aspirin should be avoided for patients with liver cirrhosis (question 23). Likewise, $68.6 \%$ of oncology nurses and $69.9 \%$ of non-oncology nurses did not understand that $25 \%$ of patients may become addicted after prolonged use of narcotics (question 21). It was also noted that the question 20 (if a patient and/or family member reports that a narcotic is causing euphoria, it should be given a lower dose) which is a correct statement, had the lowest scores in both groups (19.3\% in oncology nurses and $17.3 \%$ in non-oncology nurses).

Similar to the pharmacological pain management items, both oncology and non-oncology nurses showed a consistent pattern of answers related to non-pharmacological pain management in which correct and incorrect statements were determined appropriately. As shown in Table 3, oncology nurses scored higher in having knowledge and attitude toward non-pharmacological pain management compared to non-oncology nurses, resulting in some statistical differences due to the differences in means. None of all these items showed in Table 3 were inappropriately answered whether in oncology or non-oncology groups although, in some questions $(14,16,17$, and 22), there were significant differences between oncology and non-oncology nurses.

Table 3: Comparing oncology and non-oncology nurses in relation to the non-pharmacological pain management items.

\begin{tabular}{|c|c|c|c|c|c|}
\hline \multirow[t]{2}{*}{ Parameter } & \multicolumn{2}{|c|}{ Oncology } & \multicolumn{2}{|c|}{ Non oncology } & \multirow[t]{2}{*}{$P$ value } \\
\hline & $\begin{array}{c}\text { Correct } \\
\% \text { (a) }\end{array}$ & $\begin{array}{l}\text { Incorrect } \\
\%(\mathrm{~b})\end{array}$ & $\begin{array}{l}\text { Correct } \% \\
\text { (a) }\end{array}$ & $\begin{array}{c}\text { Incorrect } \\
\%(\mathrm{~b})\end{array}$ & \\
\hline \multirow{2}{*}{$\begin{array}{l}\text { 6-The most accurate judge of the intensity of the patient's pain is } \\
\text { the patient. (a) }\end{array}$} & 66.1 & 33.9 & 52.7 & 47.3 & \multirow[t]{2}{*}{0.093} \\
\hline & \multicolumn{2}{|c|}{ Mean: $3.58 \pm 1.098$} & \multicolumn{2}{|c|}{$3.33 \pm 1.025$} & \\
\hline \multirow{3}{*}{$\begin{array}{l}\text { 14-It is a patient's right to expect total pain relief as a } \\
\text { consequence of treatment. (a) } \\
\text { 15-Lack of pain expression does not mean lack of pain. (a) }\end{array}$} & 78.2 & 21.8 & 62.4 & 37.6 & \multirow[t]{2}{*}{$0.005 *$} \\
\hline & \multicolumn{2}{|c|}{ Mean: $3.81 \pm .899$} & \multicolumn{2}{|c|}{$3.42 \pm 1.107$} & \\
\hline & 69.3 & 30.7 & 66.7 & 33.3 & 0.680 \\
\hline & \multicolumn{2}{|c|}{ Mean: $3.68 \pm 1.166$} & \multicolumn{2}{|c|}{$3.61 \pm 1.104$} & \\
\hline \multirow{4}{*}{$\begin{array}{l}\text { 16-Distraction, for example, by the use of music or relaxation, can } \\
\text { decrease the perception of pain. (a) } \\
17 \text {-Estimation of pain by an M.D. or R.N. is as valid a measure of } \\
\text { pain as a patient's self-report. (d) }\end{array}$} & 66.1 & 33.9 & 54.9 & 45.1 & \multirow[t]{2}{*}{$0.013 *$} \\
\hline & \multicolumn{2}{|c|}{ Mean: $3.63 \pm 1.206$} & \multicolumn{2}{|c|}{$3.22 \pm 1.214$} & \\
\hline & 16.1 & 83.9 & 30.1 & 69.9 & $0.001 *$ \\
\hline & \multicolumn{2}{|c|}{ Mean: $3.80 \pm 0.954$} & \multicolumn{2}{|c|}{$3.17 \pm 1.007$} & \\
\hline \multirow[t]{2}{*}{ 22-Heat and cold should only be applied to the painful area (a) } & 64.5 & 35.5 & 51.7 & 48.3 & $0.031 *$ \\
\hline & \multicolumn{2}{|c|}{ Mean: $3.62 \pm 1.138$} & \multicolumn{2}{|c|}{$3.30 \pm .976$} & \\
\hline
\end{tabular}

(a) = Correct statement: "agree"' or "strongly agree."

$(d)=$ Incorrect statement: "disagree", " "strongly disagree. Or "either agree nor disagree"* = significant

\subsection{Summative scoring of knowledge and attitude toward pain}

Based on the summative scores of the 26 items of nurses' knowledge and attitudes toward pain, oncology nurses showed higher scores in having knowledge and positive attitude toward pain compared to non-oncology nurses showing a significant difference between both groups (mean score 72.35 Vs. 66.57, F 22.41, df 1, p<0.001).

\section{Discussion}

This study showed that there were some differences between oncology nurses and non-oncology in terms knowledge and attitude toward pain management. In particular, oncology nurses showed better grasping to pain management principles than non-oncology nurses. The difference between the two groups may refer to the educational preparation of pain management which is represented by additional educational programs or post registration training courses [21, 22 , 23, and 24]. Because the majority of oncology nurses had gained extra educational preparation for pain management, they have been more proficient in recognizing the importance of each pain management task whether pharmacological or non-pharmacological. Other research found that nurses working in oncology departments are more concerned to obtain further education about pain [5, 25, 26, and 27]. Fothergill-Bourbonnais and Wilson-Barnett [27, 28, and 29] suggested that nurses were not confident about their knowledge of analgesia because their basic education had not adequately prepared them to care for patients in pain.

However, this premise may contradict existing evidence which unveils the deficiency in nursing knowledge in pain. For instance, McCaffery \& Ferrell [30] assessed oncology nurses' knowledge toward pain management in five countries: Australia $(n=188)$, Japan $(n=805)$, Canada $(n=190)$, Spain $(n=95)$ and the USA $(n=150)$. The result of this survey revealed that nurses in all these countries have serious knowledge deficits leading to adverse effects on patient care. Likewise, a number of 374 Chinese nurses were surveyed using the Pain Knowledge and Attitude Survey Questionnaire. The study found that only $0.5 \%$ of the participants gained a passing score and the average of correct response obtained from the survey was $38.9 \%$. Similar studies reported that some nurses had a limited access to the 
knowledge related to pain and were unable to use pain assessment scales correctly or more reluctant to administer analgesics for patients with pain [29, 30, 31, 32].

Regarding questions linked to the fear of drug addiction (q 2, 4, 19, 20, 21), oncology and non-oncology nurses showed inconstancy in assuming the risk of addiction. Other research studies [14, 21, 22, 29, and 33] revealed also that nurses being less knowledgeable in the pharmacological drawback effects especially the addiction, leading to unnecessary extra precautions toward the risk of addiction. However, both oncology and non-oncology nurses exhibited a positive attitudes towards reporting pain by the patients themselves ( $q 6$ and 15). This reinforces the fact that lack of pain expression does not mean lack of pain, which was fairly understood by nurses from both groups. On the other hand, nurses recognized that self-reporting of pain is the most reliable indicator of the presence and intensity of pain, considering patients' rights to remain free of pain as much as possible [13].

The non-oncology nurses showed more confidence than oncology nurses in using aspirin and using analgesics in patients with acute abdomen (q 23 and 24). However, the most significant barrier to undertaking an effective pain management is nurses' reliance on their own subjective judgment [10,34]. To manage patient pain effectively, nurses must trust patient self-report, even if it appears incongruent with the patient's nonverbal behavior or the nurses' individual beliefs. The study suggested that the oncology nurses may underestimate or overestimate the need for pain management. This might be interpreted as Arabic clients assume that the health professionals are expertise in managing pain based on their experience and knowledge. Similar to this finding, a study [29] found the most significant barrier to effective pain management is nurses' reliance on their own subjective judgment. In another study, it was found that 29 statements that describe pain assessment were subjective and inaccurate. Nurses had reached to certain judgments based on their beliefs. For instance, nurse stated 'Patients don't really know how to rate pain, some always rate the pain the same, but they are able to sleep' [10]. Borglin et al. [34] argue that patients perceived the crucial role in increasing pain levels is that having their pain assessed incorrectly.

The study was also consistent with Fothergill-Bourbonnais and Wilson-Barnett [28] who concluded that clinical experience is the most influential factor that promotes nurses knowledge and confidence in managing patient's pain. However, some nursing practices are still based on personal opinions and rituals rather than evidence-based practice due to lack of sufficient knowledge gained from the academic experience [5, 9, 35, and 36]. The educational and clinical experience should reinforce each other; with the academic experience offering opportunity to increase a nurse's knowledge base and the clinical environment allowing them to consolidate academic learning and establish the links between theory and practice.

\section{Conclusion}

Oncology nurses scored higher in the total knowledge and attitudes toward pain management than non-oncology nurses despite both had the equal inappropriate understanding for some issues such as drug addiction. Nurses have also the correct recognition toward scoring patients' level of pain in which patient' self-reporting information is the first and reliable source of information. This study also emphasized on the educational preparations for nursing students to improve their clinical competency and independency in managing pain, which also include the assessment and interventions of pain using both pharmacological and non-pharmacological pain management techniques.

\section{Acknowledgements}

The authors wish to acknowledge these nursing staff in King Hassen Cancer Center and Al-Basher hospital for their valuable contribution in the study. We should also acknowledge the role of Zarqa University for supporting this research financially and providing the ethical approval to conduct the study.

\section{References}

[1] J.A. Davis, R.L. Robinson, L.T. Kim \& J. Xie, Incidence and impact of pain conditions and comorbid illnesses, Journal of Pain Research 4 (2011) 331-345

[2] M.K. Merboth \& S. Barnason, Managing pain: the fifth vital sign, Journal of Nursing Clinical North America 35 (2000) $375-383$.

[3] H.E. Edwards, R.E. Nash, P.M. Yates et al., Improving pain management by nurses: A pilot peer intervention program, Nursing Health Science 3 (2001) 35-45.

[4] E. Manias, M. Botti, T. Bucknall, Observation of pain assessment and management-the complexities of clinical practice, Journal of Clinical Nursing 11 (2002) 724-33.

[5] N. Rejeh, F. Ahmadi, E. Mohammadi, A. Kazemnejad \& M. Anoosheh, Nurses' experiences and perceptions of influencing barriers to postoperative pain management, Scandinavian Journal of Caring Science 23 (2009) 274-281. 
[6] A. McKinlay \& S. Cowan, Student nurses' attitudes towards working with older patients, Journal of Advanced Nursing 43 (2003) $298-309$.

[7] J. Hamilton \& L. Edgar, A survey examining nurses' knowledge of pain control, Journal of Pain and Symptom Management 7 (1992) 1826.

[8] J.L. Young, F.M. Horton \& R. Davidhizar, Nursing attitudes and beliefs in pain assessment and management, Journal of Advanced Nursing 53 (2006) 412-421.

[9] A. Jarrett, T. Church, K. Fancher-Gonzalez, K. Shackelford \& A. Lofton, Nurses' knowledge and attitudes about pain in hospitalized patients, Clinical Nurse Specialist, Lippincott Williams \& Wilkins, New York (2013).

[10] V. Prem, H. Karvannan, C. Chakravarthy, B. Binukumar, J. Saroja, P. Senthil Kumar, Attitudes and beliefs about chronic pain among nursesbiomedical or behavioral? A cross-sectional survey, Indian Journal of Palliative Care 17 (2011) 227-234.

[11] Y.K. Yildirim, F. Cicek \& M. Uyar, Knowledge and attitudes of Turkish oncology nurses about cancer pain management, Pain Management Nursing 9 (2008) 17-25.

[12] B. Wilson, Nurses' knowledge of pain, Journal of Clinical Nursing 16 (2007) 1012-1020.

[13] L.Y. Lin \& R.H. Wang, Abdominal surgery, pain and anxiety: preoperative nursing intervention, Journal of Advanced Nursing 51 (2005) 252260.

[14] J.R. Goebel, C.D. Sherbourne, S.M. Asch, L. Meredith, A.B. Cohen \& E. Hagenmaier, Addressing patients' concerns about pain management and addiction risks, Pain Management Nursing 11 (2010) 92-98.

[15] [15] L. Lui, D. So \& D. Fong, Knowledge and attitudes regarding pain among nurses in Hong Kong medical units, Journal of Clinical Nursing 17 (2008) 2014-2021.

[16] D. Al-Shaer, P.D. Hill \& M.A. Anderson, Nurses' knowledge and attitudes regarding pain assessment and intervention, Medical Surgical Nursing 20 (2011) 30-39.

[17] C. Goodrich, Students' and faculty members' knowledge and attitudes regarding pain management: a descriptive survey, Journal of Nursing Education 45 (2006) 108-117.

[18] L. Stratton, Evaluating the effectiveness of a hospital's pain management program, Journal of Nursing Care Quality 13 (1999) 8-18.

[19] H.D. Yu \& M.A. Petrini, A survey of Chinese nurses' current knowledge of pain in older people, Journal of Clinical Nursing 16 (2007) 963970.

[20] M.E. Zanolin, M. Visentin \& L. Saiani, A questionnaire to evaluate the knowledge and attitudes of health care providers on pain, Journal of pain and symptom management 33 (2007) 727-737.

[21] S. O'Brien, J.A. Dalton, G. Konsler \& J. Carlson, The knowledge and attitudes of experienced oncology nurses regarding the management of cancer-related pain, Oncology Nursing Forum 23 (1996) 515-521.

[22] P. Rushton, D. Eggett, W. Carolyn \& S. Sutherland, Knowledge and attitudes about cancer pain management: a comparison of oncology and nononcology nurses, Oncology Nursing Forum 30 (2003) 849-855.

[23] S.C. McMillan, P. Arn, M. Faan, S.J. Hagan \& B.J. Small. Training pain resource nurses: Changes in their knowledge and attitudes, Oncology Nursing Forum 32 (2005) 890-902.

[24] K. Owens, Effects of nursing education on students' pain management knowledge, Nurse Educator 25 (2000) 33-37.

[25] K.I. Kuuppeloma“, Pain management problems in patients' terminal phase as assessed by nurses in Finland, Journal of Advanced Nursing 40 (2002) 701-709.

[26] K. Lasch, A. Greenhill, G. Wilkes, D. Carr, M. Lee \& R. Blanchard, Why study pain? a qualitative analysis of medical and nursing faculty and students' knowledge of and attitudes to cancer pain management, Journal of Palliative Medicine 5 (2002) 294-308.

[27] R. King. Nurses' perceptions of their pharmacology educational needs, Journal of Advanced Nursing 45 (2004) 392-398

[28] F. Fothergill-Bourbonnais \& B. Wilson-Barnett, A comparative study of intensive therapy unit and hospice nurses' knowledge on pain management, Journal of Advanced Nursing 17 (1992) 362-372.

[29] L. Plaisance \& C. Logan, Nursing students' knowledge and attitudes regarding pain, Pain Management Nursing 7 (2006)167-175.

[30] M. McCaffery \& B.R. Ferrell, Nurses' knowledge about cancer pain: a survey of five countries, Journal of Pain and Symptom Management 10 (1995) 356-369.

[31] L. Li \& W.Q. Liu, A survey of nurses' current knowledge regarding pain, Journal of Chinese Nursing Research 17 (2003) $633-635$.

[32] H.D. Yu \& M.A. Perini, A survey of Chinese nurses' current knowledge of pain in older people, Journal of Clinical Nursing 16 (2007) 963970 .

[33] S. Shaw \& A. Lee, Student nurses' misconceptions of adults with chronic nonmalignant pain, Pain Management Nursing 11 (2010) 2-14.

[34] G. Borglin, M. Gustafsson \& H. Krona, A theory-based educational intervention targeting nurses' attitudes and knowledge concerning cancerrelated pain management: A study protocol of a quasi-experimental design, BMC Health Services Research, 11 (2011) $233-242$.

[35] M.T. Rieman \& M. Gordon, Pain management competency evidenced by a survey of pediatric nurses' knowledge and attitudes. Pediatric Nursing 33 (2007) 307-312.

[36] W. Zhi-qiang, Z. Si-yan, M. Fransen \& L. Jian-hao, Clinical attitudes towards pain treatment post-orthopedic surgery: a multicenter study in Beijing, Chinese Medical Journal 14 (2012) 2499-2504. 